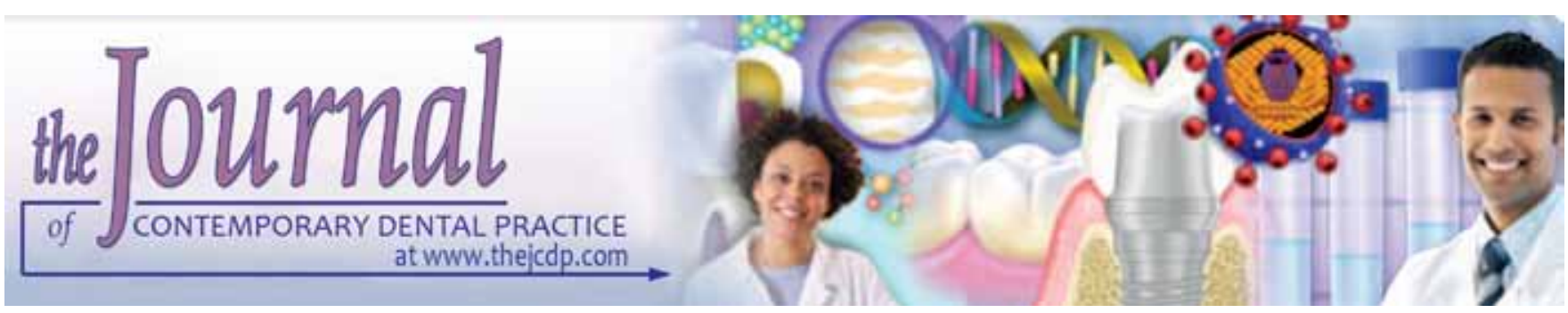

\title{
Calcium Hydroxide Dressing Influences the Obturation of Simulated Lateral Canals
}

\author{
${ }^{1}$ Karin Milena Jorge, ${ }^{2}$ Roberta Ferreira de Carvalho, ${ }^{3}$ Verena Luzia Bredt Vieira \\ ${ }^{4}$ Marilisa Carneiro Leão Gabardo, ${ }^{5}$ Letícia Machado Gonçalves, ${ }^{6}$ Marili Doro Andrade Deonizio
}

\begin{abstract}
Aim: The aim of this study was to investigate the influence of calcium hydroxide dressing on the filling of simulated lateral canals by different obturation techniques.

Materials and methods: Sixty single-root-premolars were instrumented. Simulated lateral canals were drilled on each third of the roots. The teeth were divided into four groups: no dressing and obturation by lateral condensation technique (G1), dressing with calcium hydroxide and obturation by lateral condensation technique (G2), no dressing and obturation by hybrid technique (G3) and, dressing with calcium hydroxide and obturation by hybrid technique (G4). The teeth were maintained at $37^{\circ} \mathrm{C}$ in $100 \%$ humidity for 7 days, and obturation techniques were performed. Radiographs were taken and filled or unfilled lateral canals were counted. Data were analyzed using analysis of variance (ANOVA) followed by Tukey's test $(\alpha=5 \%)$.
\end{abstract}

Results: The hybrid technique filled large number of lateral canals as compared to lateral condensation technique, regardless the use of intracanal medication $(p<0.05)$. Calcium hydroxide decreased the number of lateral canals filled for both lateral and hybrid techniques $(p<0.05)$. Significant differences were observed when comparing the number of filled and unfilled lateral canals in the same root third of each group $(p<0.05)$.

Conclusion: Regardless the obturation technique, calcium hydroxide dressing reduced the penetration of filling material in simulated lateral canals.

\footnotetext{
${ }^{1-3}$ Department of School of Health and Biosciences, Pontifícia Universidade Católica do Paraná, Paraná, Brazil

${ }^{4}$ Department of Dentistry, Universidade Positivo, Paraná, Brazil

${ }^{5}$ Department of Graduate and Postgraduate Program in Dentistry, Universidade CEUMA, Maranhão, Brazil

${ }^{6}$ Department of Dentistry, Universidade Federal do Paraná Paraná, Brazil

Corresponding Author: Marilisa Carneiro Leão Gabardo Professor, Department of Dentistry, Universidade Positivo Paraná, Brazil, Phone: +554133173180, e-mail: marilisagabardo @e-odonto.com
}

Clinical significance: The persistence of calcium hydroxide residues reduces the penetration of filling material in simulated lateral canals, possibly representing a potential cause of failure in the future.

Keywords: Calcium hydroxide, Endodontics, Root canal obturation, Laboratory research.

How to cite this article: Jorge KM, de Carvalho RF, Vieira VLB, Gabardo MCL, Gonçalves LM, Deonizio MDA. Calcium hydroxide Dressing Influences the Obturation of Simulated Lateral Canals. J Contemp Dent Pract 2015;16(6):468-473.

Source of support: Nil

Conflict of interest: None

\section{INTRODUCTION}

The root canal system has a very complex anatomy, characterized mainly by the presence of curvatures, accessory and lateral canals. ${ }^{1-3}$ The lateral canals can be observed anywhere along the root length of an important percentage of teeth, although more commonly in the apical third. ${ }^{1}$ Actually, the presence of lateral canals represents a challenge, as they are difficult to reach, clean, disinfect and fill during endodontic treatment, representing a potential cause of diseases. . $^{3,5-8}$

Considering that persisting bacteria may be located in not-accessed areas like lateral canals, the intracanal medication and three-dimensional obturation of the root system becomes extremely important. ${ }^{4}$ The intracanal medication has been used to complete the disinfection and to prevent reinfection by these microorganisms ${ }^{9-11}$ and can act chemically by killing microorganisms or physically by preventing bacterial penetration. ${ }^{12}$ The obturation also could prevent reinfection ${ }^{13}$ as the sealer isolates microorganisms without access to space and nutrients. $^{14}$

Calcium hydroxide has been widely used as an intracanal medication for its antibacterial effect on 
most of the microorganisms identified in the root canal system. ${ }^{12}$ The therapeutic properties of this medication are associated with their $\mathrm{pH}$ value and with the period they remain within the root canals. ${ }^{9,15}$ It has been pointed out that calcium hydroxide dressing for 7 days with subsequent instrumentation and irrigation with sodium hypochlorite, improves the debridement of the root canal system and efficiently eliminate persistent bacteria. ${ }^{16,17}$ However, it was found that a considerable amount of calcium hydroxide paste remains attached to the root canal after instrumentation and irrigation with various solutions. ${ }^{18-20}$ Also, it is known that when calcium hydroxide is incompletely removed from the root canal, the residue compromises the endodontic sealing. ${ }^{20,21}$ Thus, it is possible that residual calcium hydroxide could obliterate the openings of the lateral canals, blocking their filling. ${ }^{19,22}$ Additionally, the type of obturation technique is a crucial factor to be considered in such situations, since the capability to ensure the filling of lateral canals is an important clinical parameter and may represent a favorable aspect of the filling technique.

In this context, the aim of this in vitro study was to evaluate the influence of calcium hydroxide dressing on the filling of simulated lateral canals by different obturation techniques.

\section{MATERIALS AND METHODS}

The study has been approved by an ethical committee from Pontifícia Universidade Católica do Paraná, under number of register 326/2004.

Only one researcher has done the experimental procedures.

\section{Sample Preparation}

In this in vitro study, a total of 60 human single root mandibular premolars with medium length between 21 and $23 \mathrm{~mm}$ were selected. The teeth were autoclaved and stored in $0.5 \%$ thymol solution prior to the experimental assays. The coronal access was gained with a \#2 round and a \#3080 diamond bur (KG Sorensen, Barueri, São Paulo, Brazil). Then, the coronal and middle thirds of the root canal were shaped using \#1,\#2 and \#3 Gates-Glidden drills (Dentsply Maillefer, Ballaigues, Switzerland). The canal length was visually established by placing a \#10 K-file (Dentsply Maillefer, Ballaigues, Switzerland) in each root canal until it was seen emerging through the apical foramen. The working length was determined by subtracting $1 \mathrm{~mm}$ from this measurement. The teeth were instrumented at the working length using a \#35 K-file (Dentsply Maillefer, Ballaigues, Switzerland).

\section{Simulated Lateral Canals}

Three simulated lateral canals were drilled on the mesial and distal surfaces (one in each third: coronal, middle and apical) by a device. This device consisted of a \#10 K-file (Dentsply Maillefer, Ballaigues, Switzerland) with $4 \mathrm{~mm}$ from its tip sectioned, which was adapted in a low-speed contra-angle handpiece. The root canals were then instrumented using a \#45 K-file (Dentsply Maillefer, Ballaigues, Switzerland) to the working length, to create a smear layer. After every change of file size and at the completion of instrumentation, the canals were irrigated with $5 \mathrm{ml}$ of $1 \%$ sodium hypochlorite solution. Following this, the root canal was irrigated with $5 \mathrm{ml}$ of $17 \%$ ethylenediaminetetraacetic acid (EDTA) (Merck Brasil, São Paulo, Brazil) followed by a final flush of distilled water. The root canals were dried with paper points (Tanariman Manufacturer, Amazonas, AM, Brazil).

\section{Experimental Groups}

Afterwards, the 60 teeth were randomly divided into four equal groups of 15 each. The groups were separated according to the use or not of calcium hydroxide dressing, and the type of obturation technique, as follows: no dressing and obturation by lateral condensation technique (G1), dressing with calcium hydroxide and obturation by lateral condensation (G2), no dressing and obturation by Tagger's hybrid technique (G3) and, dressing with calcium hydroxide and obturation by Tagger's hybrid technique (G4).

\section{Dressing Procedure}

In G2 and G4, the calcium hydroxide paste was prepared by mixing two parts of lab grade calcium hydroxide and $1 \mathrm{ml}$ saline solution to obtain a creamy consistency. The paste was inserted using a \#25 Lentulo drill (Dentsply Maillefer, Ballaigues, Switzerland), subtracting $2 \mathrm{~mm}$ from the working length. The access cavities were temporarily sealed with a cotton pellet and temporary seal (Coltosol, Coletene, Rio de Janeiro, Brazil). The samples were maintained at $37^{\circ} \mathrm{C}$ in $100 \%$ humidity for 7 days. Afterwards, the temporary seal was removed and calcium hydroxide was cleaned using a \#35 K-file (Dentsply Maillefer, Ballaigues, Switzerland) and irrigated with $1 \%$ sodium hypochlorite solution and $17 \%$ EDTA (Merck Brasil, São Paulo, Brazil). The root canals were dried with paper points (Tanariman Manufacturer, Amazonas, Brazil).

\section{Obturation Techniques}

For obturation procedures, the AH Plus sealer (Dentsply Maillefer, Ballaigues, Switzerland) was used in all groups. 
The sealer was manipulated according to manufacturer's instructions. The obturation technique was performed as described below.

\section{Lateral Condensation}

For G1 and G2, the lateral condensation technique was used. For this, a well-fitting master gutta-percha cone \#35 (Dentsply Maillefer, Ballaigues, Switzerland) coated with sealer was taken up $1 \mathrm{~mm}$ from the working length. Then, the master cone was left seated and the lateral condensation was performed using a finger spreader B (Dentsply Maillefer, Ballaigues, Switzerland). This spreader was inserted with the sealer toward the canal's wall and then counter clock-wisely removed to create room for the insertion of the accessory gutta-percha cones (Dentsply Maillefer, Ballaigues, Switzerland). This procedure was repeated until the insertion of new accessory cones was not possible. After obturation completion, excess of filling material was removed and the cold vertical condensation was executed.

\section{Tagger's Hybrid Technique}

For G3 and G4, the Tagger's hybrid technique was used. For this, a master cone was seated as described above. An initial lateral condensation was performed with the finger spreader B (Dentsply Maillefer, Ballaigues, Switzerland), and one accessory gutta-percha cone was inserted. Next, a McSpadden compactor \#70 (Dentsply Maillefer, Ballaigues, Switzerland) was coupled to a low-speed contra-angle handpiece and introduced passively into the root canal. The penetration of the condenser inside root canal was obtained with the aid of a rubber marker $1 \mathrm{~mm}$ short of the working length. With the condenser inside the root canal, next to the gutta-percha cones, it was driven by forward and backward movements up to the working length, staying in that position for about 1 second. The condenser was removed from root canal with the motor still driven with gentle pressure on one side of the canal's wall. Following, the vertical condensation of the plasticized gutta-percha was performed through heat Paiva's condensers in order to obtain a better adaptation of the filling material.

\section{Postoperative Radiographs}

Immediately after filling, postoperative radiographs were taken and all of them were identically exposed, developed and fixed. The radiographs were placed in slide mounts and projected in order to count the lateral canals filled or unfilled in each group. Only completely filled lateral canals were considered. Three calibrated examiners analyzed the images.

\section{STATISTICAL ANALYSIS}

Data were statistically analyzed by the SAS/LAB package (SAS Software, version 9.0; SAS Institute Inc., Cary, USA). Firstly, Kappa's test was performed to evaluate the examiner's level of agreement.

The assumptions of equality of variances and normal distribution of errors were checked and the data were transformed as suggested by the software. The simulated lateral canals were analyzed using three-way analysis of variance (ANOVA) followed by Tukey's HSD test, considering the dressing, obturation technique and root thirds as study factors. The significance level was set at 5\%.

\section{RESULTS}

The value of the test of agreement between examiners was 0.89 .

In Figure 1, representative radiographs after obturation by different techniques have been shown.

The Tagger's hybrid technique filled large number of simulated lateral canals as compared to the lateral condensation technique, regardless the use of intracanal medication $(p<0.05)$. Moreover, it was shown that the use of calcium hydroxide decreased the number of simulated lateral canals filled for both lateral and hybrid condensation techniques $(\mathrm{p}<0.05)$ (Graph 1$)$.

Although the coronal and apical thirds had a somewhat larger number of filled lateral canals than the middle third, this difference was not statistically significant ( $p>0.05)$ (Table 1). Significant differences were observed when comparing the number of filled and unfilled canals in the same root third of each group ( $p<0.05)$. Overall, no differences were found among the different root thirds in the same group ( $p>0.05)$.

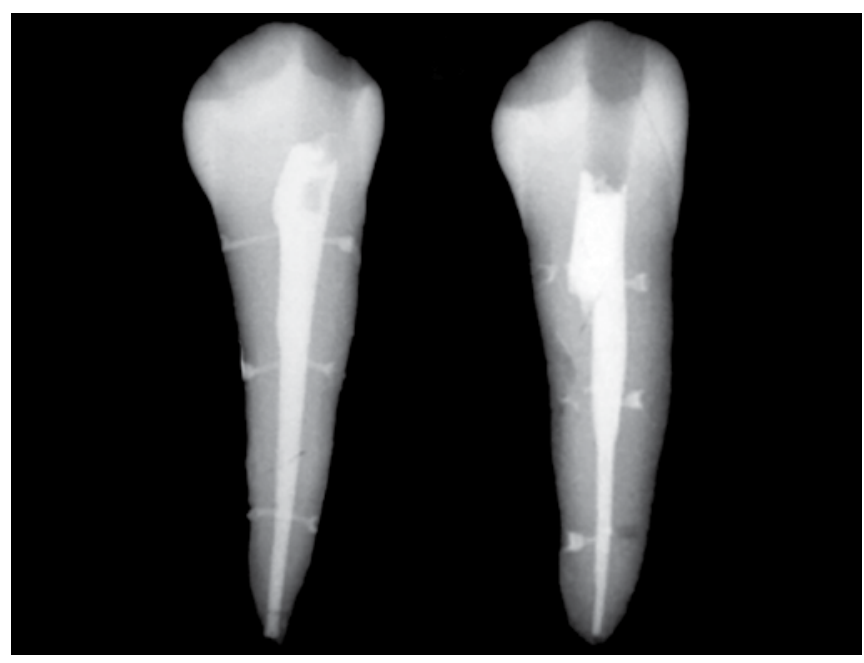

Fig. 1: Representative radiographs after obturation by different techniques 
Table 1: Number of filled and unfilled simulated lateral canals according to the group and different thirds of the root in which they were located

\begin{tabular}{|c|c|c|c|c|c|c|c|c|}
\hline \multirow[b]{2}{*}{ Location } & \multicolumn{2}{|c|}{ G1 } & \multicolumn{2}{|c|}{ G2 } & \multicolumn{2}{|c|}{ G3 } & \multicolumn{2}{|c|}{ G4 } \\
\hline & Filled & Unfilled & Filled & Unfilled & Filled & Unfilled & Filled & Unfilled \\
\hline Coronal & $23 \mathrm{~A}, \mathrm{a}$ & $07 \mathrm{~B}, \mathrm{a}$ & $18 \mathrm{~A}, \mathrm{a}$ & $12 \mathrm{~B}, \mathrm{a}$ & $20 \mathrm{~A}, \mathrm{a}$ & $10 \mathrm{~B}, \mathrm{a}$ & $19 \mathrm{~A}, \mathrm{a}$ & $11 \mathrm{~B}, \mathrm{a}$ \\
\hline Middle & $19 \mathrm{~A}, \mathrm{a}$ & $11 \mathrm{~B}, \mathrm{a}$ & $07 \mathrm{~A}, \mathrm{~b}$ & $23 \mathrm{~B}, \mathrm{~b}$ & $23 \mathrm{~A}, \mathrm{a}$ & $07 \mathrm{~B}, \mathrm{a}$ & $21 \mathrm{~A}, \mathrm{a}$ & 09 B,a \\
\hline Apical & $20 \mathrm{~A}, \mathrm{a}$ & $10 \mathrm{~B}, \mathrm{a}$ & $15 \mathrm{~A}, \mathrm{a}$ & $15 \mathrm{~A}, \mathrm{a}$ & $24 \mathrm{~A}, \mathrm{a}$ & $06 \mathrm{~B}, \mathrm{a}$ & 19 A,a & $11 \mathrm{~B}, \mathrm{a}$ \\
\hline
\end{tabular}

Different uppercase letters indicate significant differences between filled and unfilled canals in the same root third of each group. Different lowercase letters indicate significant differences between filled or unfilled lateral canals among the different root third of each group. (ANOVA, $p<0.05$ )

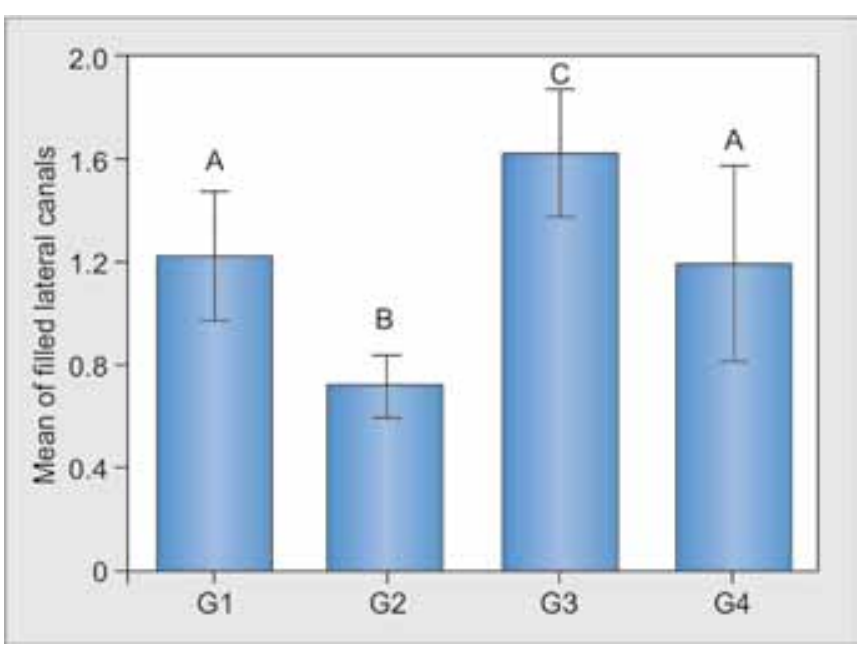

Graph 1: Mean of filled simulated lateral canals according to the groups. Different letters indicate significant differences between groups (ANOVA, $\mathrm{p}<0.05$ )

\section{DISCUSSION}

After shaping and cleaning the root canal, persisting bacteria may be located in not-accessed areas like lateral canals. This must be considered potentially pathogenic and a cause of future endodontic failure. ${ }^{3,5-8}$ For this reason, dressing and three-dimensional obturation of the root canal system become important steps. ${ }^{4}$

The use of calcium hydroxide dressing is established in the literature, ${ }^{23}$ however, persistence of this medication in the root canal walls could prevent the sealer penetration into the dentinal tubules, ${ }^{21}$ compromising the obturation procedure. Also, several techniques have been developed to achieve an adequate three-dimensional obturation of lateral canals. ${ }^{24}$ For this, we aimed to evaluate the influence of calcium hydroxide dressing on the filling of simulated lateral canals by different obturation techniques.

The actual need to fill lateral canals has been a largely discussed in the current literature. ${ }^{2,4,19}$ However, it is important to point out that both lateral canals and apical ramifications have been implicated with treatment failure when they are sufficiently large to harbor significant numbers of bacteria and to provide these bacteria access to the periradicular tissues. ${ }^{3,25}$ Therefore, disinfection, dressing and filling of lateral canals in cases of pulp necrosis and apical and/or lateral periodontitis should be considered important goals of the treatment, although difficult to achieve. ${ }^{3}$

Calcium hydroxide is widely used as an intracanal medication, 12 and several techniques have been used to remove it from the root canal. ${ }^{18,21,26,27}$ The enlargement of the canal to the next file size and copious irrigation with sodium hypochlorite and/or EDTA, which are the procedures commonly used in clinical practice, seem to be unable in completely removing calcium hydroxide from root canal. ${ }^{21,26}$ There is a consensus that the residues of the medicament persist in the canal even with different techniques for removal. ${ }^{28,29}$

The results of our study demonstrated that residual calcium hydroxide blocked the openings of the lateral canals, reducing and/or preventing the penetration of sealer or gutta-percha into the lateral canals, corroborating with a previous study. ${ }^{19}$ Regardless the obturation technique, we demonstrated that when calcium hydroxide was applied as a dressing medication (G2 + G4), 99 of the 180 simulated lateral canals were obturated. On the other hand, when calcium hydroxide was not used (G1 + G3), 129 of the 180 simulated lateral canals were filled. Also, in our study, simulated lateral canals were created in each third of the canal root. We showed that no differences were found among the different root thirds in the same group. About the ability of different obturation techniques to fill simulated lateral canals, the literature indicates that warm gutta-percha techniques are superior. ${ }^{2}$

According to our results, the Tagger's hybrid technique resulted in large number of filled simulated lateral canals, although it was reduced with the dressing with calcium hydroxide. Also, the lateral condensation showed the worst ability in filling simulated lateral canals, particularly when calcium hydroxide dressing was employed. It is possible that the cold condensation of gutta-percha difficult the penetration of the filling material. ${ }^{30}$ Thermoplasticized techniques improve the expansion of the material against the dentinal walls. ${ }^{31}$

A recent study about the interference of calcium hydroxide previous to the filling revealed that the medication can difficult the hermetic filling of the root canal system because of its property of obliterates lateral canals. ${ }^{22}$ 
Overall, the persistence of calcium hydroxide residues should be considered as a side-effect when selecting this medication as an inter-appointment dressing in root canal therapy, ${ }^{19,22}$ regardless the obturation technique to be employed.

\section{CONCLUSION}

Regardless the obturation technique, calcium hydroxide dressing reduced the penetration of filling material in simulated lateral canals.

\section{CLINICAL SIGNIFICANCE}

The persistence of calcium hydroxide residues reduces the penetration of filling material in simulated lateral canals, possibly representing a potential cause of failure in the future.

\section{REFERENCES}

1. De Deus QD. Frequency, location, and direction of the lateral, secondary and accessory canals. J Endod 1975 Nov;1(11): 361-366.

2. Goldberg F, Artaza LP, De Silvio A. Effectiveness of different obturation techniques in the filling of simulated lateral canals. J Endod 2001 May;27(5):362-364.

3. Ricucci D, Siqueira JF Jr. Fate of the tissue in lateral canals and apical ramifications in response to pathologic conditions and treatment procedures. J Endod 2010 Jan;36(1):1-15.

4. Carvalho-Sousa B, Almeida-Gomes F, Carvalho PR, ManigliaFerreira C, Gurgel-Filho ED, Albuquerque DS. Filling lateral canals: evaluation of different filling techniques. Eur J Dent 2010 Jul;4(3):251-256.

5. Seltzer S, Bender IB, Smith J, Freedman I, Nazimov H. Endodontic failures-an analysis based on clinical, roentgenographic, and histologic findings. II. Oral Surg Oral Med Oral Pathol 1967 Apr;23(4):517-530.

6. Seltzer S, Bender IB, Smith J, Freedman I, Nazimov H. Endodontic failures-an analysis based on clinical, roentgenographic, and histologic findings. Oral Surg Oral Med Oral Pathol 1967 Apr;23(4):500-516.

7. Weine FS. The enigma of the lateral canal. Dent Clin North Am 1984 Oct;28(4):833-852.

8. Silveira CF, Martos J, Neto JB, Ferrer-Luque CM, Silveira LF. Clinical importance of the presence of lateral canals in endodontics. Gen Dent 2010 Mar-Apr;58(2):e80-83.

9. Siqueira JF Jr, Lopes HP. Mechanisms of antimicrobial activity of calcium hydroxide: a critical review. Int Endod J 1999 Sep;32(5):361-369.

10. Law A, Messer H. An evidence-based analysis of the antibacterial effectiveness of intracanal medicaments. J Endod 2004 Oct;30(10):689-694.

11. Silveira CF, Cunha RS, Fontana CE, de Martin AS, Gomes BP, Motta RH, Bueno CE. Assessment of the antibacterial activity of calcium hydroxide combined with chlorhexidine paste and other intracanal medications against bacterial pathogens. Eur J Dent 2011 Jan;5(1):1-7.
12. Farhad AR, Barekatain B, Allameh M, Narimani T. Evaluation of the antibacterial effect of calcium hydroxide in combination with three different vehicles: An in vitro study. Dent Res J (Isfahan) 2012 Mar;9(2):167-172.

13. Pinheiro ET, Gomes BP, Ferraz CC, Sousa EL, Teixeira FB, Souza-Filho FJ. Microorganisms from canals of root-filled teeth with periapical lesions. Int Endod J 2003 Jan;36 (1):1-11.

14. Vivacqua-Gomes N, Gurgel-Filho ED, Gomes BP, Ferraz CC, Zaia AA, Souza-Filho FJ. Recovery of enterococcus faecalis after single-or multiple-visit root canal treatments carried out in infected teeth ex vivo. Int Endod J 2005 Oct;38(10): 697-704.

15. Pacios MG, de la Casa ML, de Bulacio M, Lopez ME. Influence of different vehicles on the $\mathrm{pH}$ of calcium hydroxide pastes. J Oral Sci 2004 Jun;46(2):107-111.

16. Metzler RS, Montgomery S. Effectiveness of ultrasonics and calcium hydroxide for the debridement of human mandibular molars. J Endod 1989 Aug;15(8):373-378.

17. Sjogren U, Figdor D, Spangberg L, Sundqvist G. The antimicrobial effect of calcium hydroxide as a short-term intracanal dressing. Int Endod J 1991 May;24(3):119-125.

18. Lambrianidis T, Margelos J, Beltes P. Removal efficiency of calcium hydroxide dressing from the root canal. J Endod 1999 Feb;25(2):85-88.

19. Goldberg F, Artaza LP, De Silvio. Influence of calcium hydroxide dressing on the obturation of simulated lateral canals. J Endod 2002 Feb;28(2):99-101.

20. Khaleel HY, Al-Ashaw AJ, Yang Y, Pang AH, Ma JZ. Quantitative comparison of calcium hydroxide removal by endoactivator, ultrasonic and protaper file agitation techniques: an in vitro study. J Huazhong Univ Sci Technolog Med Sci 2013 Feb;33(1):142-145.

21. Calt $S$, Serper A. Dentinal tubule penetration of root canal sealers after root canal dressing with calcium hydroxide. J Endod 1999 Jun;25(6):431-433.

22. Vilela DD, Neto MM, Villela AM, Pithon MM. Evaluation of interference of calcium hydroxide-based intracanal medication in filling root canal systems. J Contemp Dent Pract 2011 Sep1;12(5):368-371.

23. Mohammadi Z, Shalavi S, Yazdizadeh M. Antimicrobial activity of calcium hydroxide in endodontics: a review. Chonnam Med J 2012 Dec;48(3):133-140.

24. Schafer E, Nelius B, Burklein S. A comparative evaluation of gutta-percha filled areas in curved root canals obturated with different techniques. Clin Oral Investig 2012 Feb;16(1): 225-230.

25. Ricucci D, Siqueira JF Jr, Bate AL, Pitt Ford TR. Histologic investigation of root canal-treated teeth with apical periodontitis: a retrospective study from twenty-four patients. J Endod 2009 Apr;35(4):493-502.

26. Porkaew P, Retief DH, Barfield RD, Lacefield WR, Soong SJ. Effects of calcium hydroxide paste as an intracanal medicament on apical seal. J Endod 1990 Aug;16(8):369-374.

27. Tatsuta CT, Morgan LA, Baumgartner JC, Adey JD. Effect of calcium hydroxide and four irrigation regimens on instrumented and uninstrumented canal wall topography. J Endod 1999 Feb;25(2):93-98.

28. Kuga MC, Tanomaru-Filho M, Faria G, Só MV, Galletti T, Bavello JR. Calcium hydroxide intracanal dressing removal with different rotary instruments and irrigating solutions: 
a scanning electron microscopy study. Braz Oral Res 2010;21(4):310-314.

29. Kuga MC, Campos EA, Faria-Junior NB, Só MV, Shinohara AL. Efficacy of NiTi rotary instruments in removing calcium hydroxide dressing residues from root canal walls. Braz Oral Res 2012 Jan-Feb;26(1):19-23.
30. Luccy CT, Weller RN, Kulild JC. An evaluation of the apical seal produced by lateral and warm lateral condensation techniques. J Endod 1990 Apr;16(4):170-172.

31. Tortini D, Grassa M, Re Cecconi D, Colombo M, Gagliani M. Warm gutta-percha obturation technique: a critical review. Minerva Stomatol 2011 Jan-Feb;60(1-2):35-50. 